\title{
Quantifying long-term discards from Queensland's (Australia) east Coast otter trawl fishery
}

\author{
Na Wang ${ }^{1}$, Anthony J. Courtney (D) ${ }^{1 *}$, Matthew J. Campbell ${ }^{1}$, and Wen-Hsi Yang ${ }^{2}$ \\ ${ }^{1}$ Department of Agriculture and Fisheries, Brisbane, Queensland 4001, Australia \\ ${ }^{2}$ Centre for Applications in Natural Resource Management, School of Mathematics and Physics, The University of Queensland, St Lucia, \\ Queensland 4072, Australia \\ *Corresponding author: tel: 6170434075410 ; e-mail: Tony.Courtney@daf.qld.gov.au.
}

Wang, N., Courtney, A. J., Campbell, M. J., and Yang, W.-H. Quantifying long-term discards from Queensland's (Australia) east Coast otter trawl fishery. - ICES Journal of Marine Science, doi:10.1093/icesjms/fsz205.

Received 1 July 2019; revised 25 September 2019; accepted 6 October 2019.

\begin{abstract}
This article estimated the weight of annual discards in the Queensland east coast otter trawl fishery. Discards data were analysed using three generalized linear mixed models to derive adjusted discard rates, expressed as $\mathrm{kg}$ per retained catch, $\mathrm{kg}$ per boat day, and $\mathrm{kg}$ per area swept by trawls, respectively. Model explanatory terms included trawl fishing sector, presence/absence of bycatch reduction devices (BRDs), lunar phase, and whether the data were obtained from commercial vessels during their normal fishing activities or during research charters. Adjusted discard rates were then used to derive three estimates of annual discards and the average used to examine a long-term discard trends from 1988 to 2014. Total discards declined significantly from a peak of approximately $67000 \mathrm{t}$ in 1997 to approximately $21000 \mathrm{t}$ from 2011 to 2014, largely due to a decline in fishing effort, and to a lesser degree, the effects of BRDs that were mandated in the fishery in the early 2000s.
\end{abstract}

Keywords: BRD, bycatch reduction devices, discard rates, fishing effort, prawns, saucer scallops, swept area, trawl bycatch, trawl discards

\section{Introduction}

Fishery discards, particularly those generated by commercial fisheries, continue to generate significant regional, national, and global concern (Davies et al., 2009; Rochet et al., 2014; Pérez Roda et al., 2019). For most fisheries, the amount of discards is unknown because it is generally too difficult and impractical for fishers to record such information during normal fishing activities. As a result, total discards are usually estimated and based upon discard rates obtained from observer programmes or research projects that sample temporal and spatial "windows" of fishing activity.

Several authors have estimated global discards. Alverson et al. (1994) estimated an annual mean of 27.0 million tonne $(t)$, based on catch data from 1988 to 1990 , but more recent estimates have been significantly lower and relatively consistent, varying from 7.3 million t to slightly less than 10.0 million $t$ (Kelleher, 2005; Zeller et al., 2018; Pérez Roda et al., 2019). Shrimp (prawn) trawling has the highest discard rate compared to any other fishing method and accounts for 27-35\% of total global discards (Alverson et al., 1994; Kelleher, 2005). The apparent decline in global discards since the 1980s has been attributed to increased utilization of catches, reduced effort in some major trawl fisheries, and improved management, including more selective fishing. The EU Common Fisheries Policy reforms, which require all listed species caught to be landed, have also contributed to significant discard reductions (Condie et al., 2014; Rochet et al., 2014).

In Australia, bycatch mitigation plans have been implemented for most fisheries and include the mandatory use of bycatch reduction devices (BRDs) in all prawn trawl fisheries (Gullet, 2003). While several studies have quantified the effects of BRDs on catch rates (Broadhurst et al., 2004; Brewer et al., 2006; Kennelly and Broadhurst, 2014), there are few published estimates of the amount of discards generated in Australian fisheries. An exception is Kennelly et al. (1998), who used observer data to derive an estimate of $13458 \mathrm{t}$ of discards in the New South Wales oceanic prawn trawl fishery over a 2-year period (1990-1992) for 
a retained prawn catch of 1579 t. Kelleher (2005) estimated that Australia produced $120981 \mathrm{t}$ of discards annually (1992-2001) with a mean discard rate of $55 \%$.

The Queensland east coast otter trawl fishery (QECOTF) is the largest prawn trawl fishery in Australia, in terms of fishing effort and number of licensed vessels, which peaked at over 1400 in the 1980s (Hill and Pashen, 1986) but has declined since to 429 in 2014. Data from a mandatory logbook programme introduced in 1988 indicate that from 1988 to 2014 fishing effort ranged between 114267 boat days in 1997 and 32861 boat days in 2013. Management measures used to constrain the effects of fishing include restrictions on vessel length and total net head rope length used by each vessel, and an effort unit allocation system that determines how many days a vessel can trawl annually. In 2015, 1.63 million effort units were used from the 2.76 million total allocated units, or about $59 \%$, indicating considerable latent or unused effort. Total landings, which are mainly composed of penaeid prawns, saucer scallops, stout whiting, and scyllarid lobsters, have ranged between $8222 \mathrm{t}$ in 2011 and $20013 \mathrm{t}$ in 1993.

Discards from the QECOTF are contentious, not only because of the relatively high annual fishing effort and discard rate characteristic of prawn trawl fisheries, but because most of the fishery occurs in the Great Barrier Reef Marine Park, which is a World Heritage Area (Figure 1). Previous research on the fishery's discards has focused on protected species of sea turtles (Robins, 1995) and sea snakes (Courtney et al., 2010; Elfes et al., 2013), discards composition (Watson and Goeden, 1989; Watson et al., 1990), benthic impacts (Pitcher et al., 2016), and BRD testing (Robins-Troeger, 1994; Robins-Troeger et al., 1995; Courtney et al., 2008, 2014). Despite this and the implementation of discard management measures, the amount of discards generated by the QECOTF remains unknown (Robins and Courtney, 1998). The objective of the present study is to quantify long-term trends in the fishery's annual discards. The results can be used to evaluate discard management measures and the methods may have application in other fisheries.

\section{Material and methods Definitions}

Our definition of discards is similar to that used by Kelleher (2005), which was adopted from the FAO Fisheries Report No. 547 (FAO, 1997). We define discards as the weight of organic matter that is returned to the sea by the fishers, which differs slightly from Kelleher's as we include coral rubble and plants (i.e. algae and seagrass), which comprise a very minor component of the QECOTF discards (i.e. $<1 \%$ ).

The retained catch weight is composed largely of the "principal species" (i.e. targeted species) and to a lesser degree "permitted species" (i.e. byproduct), as defined in the QECOTF Management Plan (State of Queensland 1999). Principal species are penaeid prawns (Penaeus spp., Melicertus spp., Metapenaeus spp. Fenneropenaeus spp.), saucer scallops (Ylistrum balloti), scyllarid lobsters (Thenus spp.), and stout whiting (Sillago robusta). Permitted species are portunid crabs (Portunus spp.), Balmain Bugs (Ibacus spp.), cuttlefish (Sepia spp.), barking crayfish (Linuparus trigonus), octopus (Octopus spp.), squid (Loligo spp.), mantis shrimp (Squilla spp., Oratosquilla spp.), pipefish (Solegnathus spp.), and threadfin breams (Nemipterus spp.).

Discards can include target and byproduct species that are not retained for various reasons, as determined by individual fishers (e.g. undersize or sub-optimal individuals, poor prices or low demand, small or inconsistent catches that are difficult to market). About 1300 taxa have been reported in the fishery's discards (Watson et al., 1990; Courtney et al., 2007b). Numerically, common fish and invertebrate species include the gurnard (Lepidotrigla argus), lizard fish (Saurida spp.), dragonets (Callionymus spp.), the longspine emperor (Lethrinus genivittatus), Caledonian stinger (Inimicus caledonicus), portunid crab (Portunus rubromarginatus), three-spined cardinalfish (Apogonops anomalus), orange-freckled flathead (Ratabulus diversidens), and sponges (Callypongia spp.).

\section{Estimating total discards}

Three methods for quantifying discards were used: (i) retained catch method, where discard weight is a function of the retained catch reported in the mandatory Queensland logbook database programme, (ii) effort method, where discard weight is a function of the amount of fishing effort, also reported in logbook data (i.e. boat days), and (iii) swept area method, where discard weight is a function of the bottom area in hectares (ha) swept by the fleet.

The QECOTF was stratified into eight sectors, based on location, target species, fishing gear, and depth (Table 1). The methods used data on catch, gear (i.e. net size and configuration), and fishing effort reported in the logbook database to estimate discards from January 1988 (when the logbook commenced) to December 2014. Discard rates were modelled using sector as a categorical term for all sectors except for the stout whiting fishery. This is because the stout whiting fishery is a relatively small fishery that commenced in the 1990s under a separate license that was restricted to five license holders specifically to harvest whiting. While the stout whiting fishery commenced using prawn trawl nets, most vessels have deployed single large nets with extended sweeps used for "herding" the whiting and since 2007 some operators have been deployed Danish seine methodology. For these reasons, discard rates for the stout whiting fishery were modelled separately from the other sectors, which target prawns, and scallops.

\section{Retained catch method}

Estimating discards as a proportion of total catch (i.e. retained catch + discards) is the most common method used to quantify discards and was used by Kelleher (2005) and Pérez Roda et al.(2019) to derive global estimates. This is because catch is the only available metric to predict discards in many fisheries. In the present study, the proportion of discards was based on 3436 paired measures of discards and retained catch in QECOTF sectors between 1996 and 2010. Discard rates from these data can be expressed as discards $(\mathrm{kg})$ per retained catch $(\mathrm{kg})$ (i.e. $\mathrm{kg} \mathrm{kg}^{-1}$ ). The data were obtained by fishery observers and researchers aboard commercial trawlers that were undertaking their normal fishing activities, as well as research charters that were designed to evaluate BRDs in the trawl fishing grounds. Further details of the sampling methods used to collect the data can be found in Robins et al. (2000), Stobutzki et al. (2000), and Courtney et al. (2006, 2007a, b, 2008, 2014).

For each paired measure, the following candidate explanatory terms were recorded:

(1) sector (categorical term, seven classes plus the stout whiting fishery which was considered separately, Table 1); 


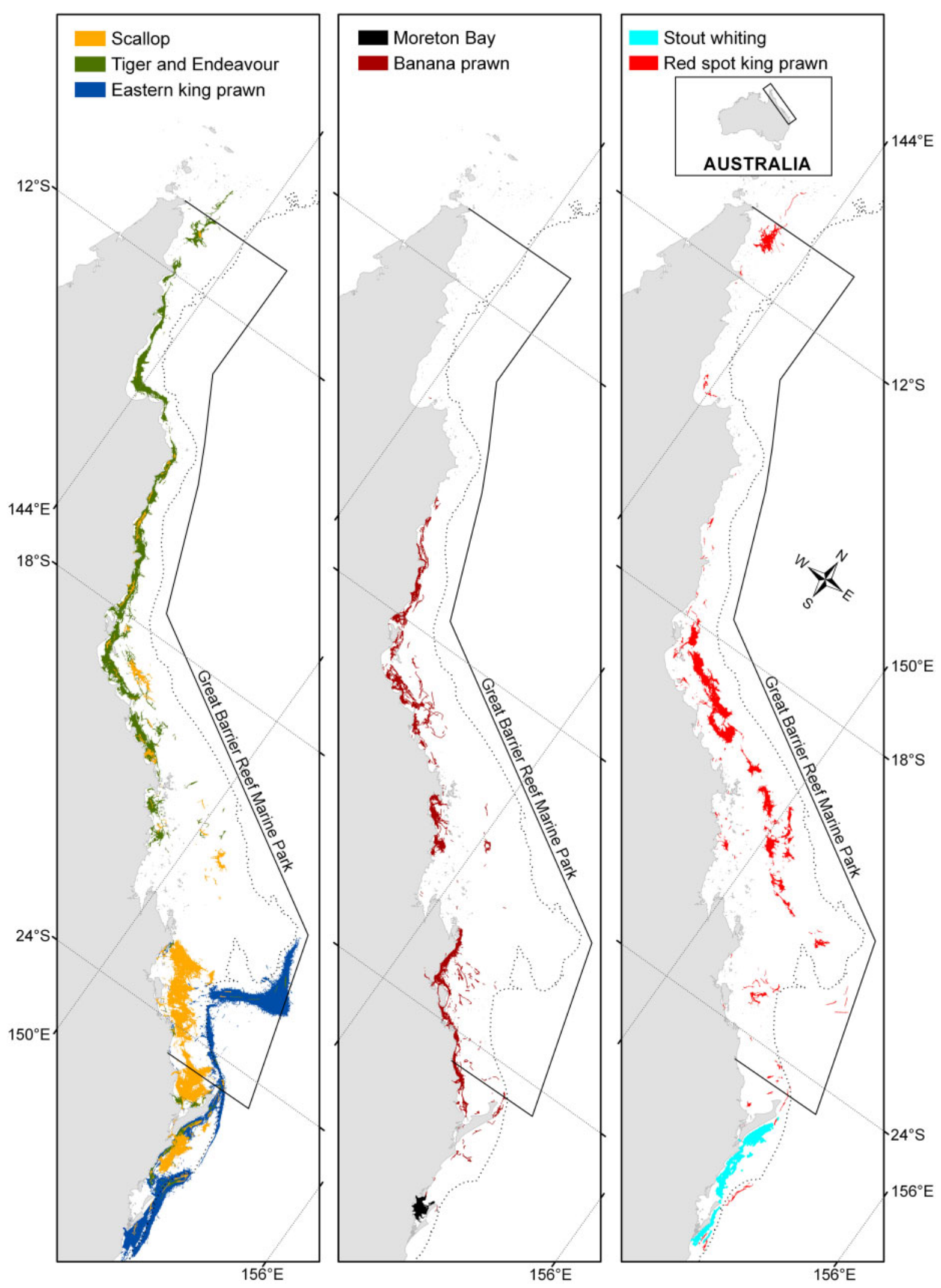

Figure 1. Spatial distribution of catch from the Queensland east coast otter trawl fishery based on mandatory reported logbook catch data and vessel monitoring system (VMS) locational data. The fishery can be partitioned into eight sectors, with the eastern king prawn fishery broken down further to shallow ( $<50$ fathoms) and deep ( $>50$ fathoms). Dotted line is the approximate 50 fathom depth contour. 
Table 1. Details and descriptions of the eight sectors that comprise the QECOTF.

\begin{tabular}{|c|c|c|c|}
\hline & Sector & Target species & Details \\
\hline 1 & Tiger and endeavour prawn & $\begin{array}{l}\text { Brown tiger prawn Penaeus esculentus, grooved tiger prawn } \\
\text { Penaeus semisulcatus, blue tail endeavour prawn Metapenaeus } \\
\text { endeavouri, and red endeavour prawn Metapenaeus ensis }\end{array}$ & $\begin{array}{l}11.0-22.0^{\circ} \mathrm{S} \text {. Generally in depths }<30 \mathrm{~m} . \\
\text { Maximum net size of } 88 \mathrm{~m}\end{array}$ \\
\hline 2 & Red spot king prawn & $\begin{array}{l}\text { Red spot king prawn Melicertus longistylus and minor catches of } \\
\text { blue-legged king prawn Melicertus latisulcatus }\end{array}$ & $\begin{array}{l}11.0-22.0^{\circ} \mathrm{S} \text {. Generally in depths } 30-70 \mathrm{~m} \text {. } \\
\text { Maximum net size of } 88 \mathrm{~m}\end{array}$ \\
\hline 3 & $\begin{array}{l}\text { Shallow water eastern } \\
\text { king prawn }\end{array}$ & Eastern king prawn Melicertus plebejus & $\begin{array}{l}22.0-28.3^{\circ} \mathrm{S} \text { in depths }<91 \mathrm{~m} \text { ( } 50 \text { fathoms). } \\
\text { Maximum net size of } 88 \mathrm{~m}\end{array}$ \\
\hline 4 & $\begin{array}{l}\text { Deep water eastern } \\
\text { king prawn }\end{array}$ & Eastern king prawn Melicertus plebejus & $\begin{array}{l}22.0-28.3^{\circ} \mathrm{S} \text { in depths } \geq 91 \mathrm{~m} \text { ( } 50 \text { fathoms). } \\
\text { Maximum net size of } 184 \mathrm{~m}\end{array}$ \\
\hline 5 & Banana prawn & Banana prawn Fenneropenaeus merguiensis & $\begin{array}{l}16.0-28.3^{\circ} \mathrm{S} \text { in }<30 \mathrm{~m} \text {, mainly February and } \\
\text { June. Maximum net size of } 88 \mathrm{~m}\end{array}$ \\
\hline 6 & Saucer scallop & Saucer scallop Ylistrum balloti & $\begin{array}{l}22.0-27.0^{\circ} \mathrm{S} \text { in } 20-60 \mathrm{~m} \text {. Maximum net size }{ }^{\mathrm{a}} \\
\text { of } 109 \mathrm{~m} \text {. Minimum codend mesh size of } \\
75 \mathrm{~mm}\end{array}$ \\
\hline 7 & Moreton Bay & $\begin{array}{l}\text { Greentail prawn Metapenaeus bennettae, brown tiger prawn } \\
\text { P. esculentus, and juvenile eastern king prawn M. plebejus }\end{array}$ & $\begin{array}{l}\text { Within Moreton Bay. Maximum vessel length } \\
\text { of } 14 \mathrm{~m} \text {. Maximum net size of } 32.5 \mathrm{~m}\end{array}$ \\
\hline 8 & Stout whiting & Sillago robusta & $\begin{array}{l}24.4-28.3^{\circ} \mathrm{S} \text { in depths of } 37-91 \mathrm{~m}(20-50 \\
\text { fathoms). Limited to five licenses and } \\
\text { managed using annual total allowable catch } \\
\text { (TAC). Fishery commenced using prawn } \\
\text { trawl nets, then progressed to using single } \\
\text { otter trawl with } 128 \mathrm{~m} \text { sweeps or Danish } \\
\text { seine with } 2 \times 2500 \mathrm{~m} \text { haul ropes }\end{array}$ \\
\hline
\end{tabular}

${ }^{a}$ Net size refers to the combined length of the head rope and foot rope for all nets used on the vessel.

(2) sampling trip (random sample of fishing excursions, which ranged in duration from 2 to 10 days);

(3) trawl shot number (random sample of completed deployments of the trawl gear which consisted of towing 1-5 nets simultaneously);

(4) lunar phase (covariate based on lunar luminance which ranges between 0 for new moon to 1 for full moon);

(5) lunar phase advanced 7 days [same as lunar phase except the phase is advanced 7 days to account for the increasing (waxing) or decreasing (waning) luminance];

(6) sampling programme (a binary term differentiating commercial fishing and research charters); and

(7) presence of a BRD in the net/s [binary term where a BRD was defined as a turtle excluder device (TED) or any other device designed for excluding bycatch, or both].

The logistic-binomial regression model of hierarchical generalized linear models (i.e. generalized linear mixed models or GLMMs) was applied to model the proportion $\pi_{c}$ of discards in the total catch weight. To fit a logistic regression model, the weights of retained catch and discards were rounded to the nearest integer (i.e. no decimals). The logit link function was used such that $\pi_{c}$ was related to covariates as follows:

$$
\ln \left(\frac{\pi_{c}}{1-\pi_{c}}\right)=\alpha_{c}+\boldsymbol{x}_{c}^{t} \boldsymbol{\beta}_{\mathrm{c}}+\boldsymbol{z}_{c}^{t} \boldsymbol{b}_{c}
$$

where $\alpha_{c}$ is the intercept, $\mathbf{x}_{\mathrm{c}}$ and $\boldsymbol{z}_{c}$ are the column vectors of covariates for fixed and random effects, respectively, and $\boldsymbol{\beta}_{\mathrm{c}}$ and $\boldsymbol{b}_{c}$ are the column vectors of coefficients for fixed and random effects, respectively. Subscript $t$ refers to a vector transposed hereafter. For all trawl sectors excluding stout whiting, $\boldsymbol{x}_{c}$ includes sector, $\mathrm{BRD}$, the interaction between sector and $\mathrm{BRD}$, sampling programme, lunar phase and lunar phase advanced 7 days, and $\boldsymbol{z}_{c}$ the interaction between sector and trawl shot number. For the stout whiting fishery, $\boldsymbol{x}_{c}$ included the effect of gear type (i.e. trawl net or Danish seine), lunar phase, and lunar phase advanced 7 days, and $z_{c}$ the interaction between gear type and sampling trip. Sampling trip and trawl shot number were random terms nested within sector and the number of observations for each trip and trawl shot were unequal. Because the stout whiting fishery developed relatively recently, all discard measures for this fishery were obtained after TEDs were mandated for use in all towed nets in Queensland in 2000, and therefore it was not possible to evaluate the BRD effects in this sector.

\section{Effort method}

The same data were used for this method except that the research charter data were omitted. This is because the charters produced fewer discards per boat day than an average commercial trawling day due to the need to impose experimental control, which included increased travel/steaming to and from predetermined sites (hence less trawling time), undertaking trawls of shorter duration to obtain adequate replication, and time spent swapping experimental gears (i.e. BRDs and codends) between trawls.

Discard rates ( $\mathrm{kg}$ boat day ${ }^{-1}$ ) were calculated by summing discards from all trawls from a vessel on a given boat day. As most of the target species in the fishery are nocturnal and therefore more catchable at night, a boat day was defined as 12:00 pm to 12:00 pm. For banana prawns, which are atypical and mainly active during daylight hours, a boat day in this sector was defined as 12:00 am to 12:00 am. Because the data were restricted to commercial vessels undertaking normal fishing activities and summed to whole boat days, the number of observations was reduced to 381 boat days. Summing data to whole boat days meant variation 
between trawls could not be considered and so trawl shot number was dropped from the model. For sampling trips on board vessels where a BRD was installed in half of the nets and not installed in the other half (e.g. for comparative purposes), the observations from each net were doubled to represent whole boat days.

The gamma regression model of GLMMs was applied to model the discard rate in $\mathrm{kg}$ boat day ${ }^{-1}$ and a log link function was used to relate $\mu_{e}$, the expectation of each measure, to covariates with the following form,

$$
\ln \left(\mu_{e}\right)=\alpha_{e}+\boldsymbol{x}_{e}^{t} \boldsymbol{\beta}_{\mathrm{e}}+\boldsymbol{z}_{e}^{t} \boldsymbol{b}_{e}
$$

where $\alpha_{e}$ is the intercept, $\boldsymbol{x}_{e}$ and $\boldsymbol{z}_{e}$ are the column vectors of covariates for fixed and random effects, respectively, and $\boldsymbol{\beta}_{\mathrm{e}}$ and $\boldsymbol{b}_{e}$ are their associated coefficients, respectively. A gamma distribution was used because it often best describes the attributes of trawl discard data, including a lack of zero observations (Courtney et al., 2008, 2014). For all sectors, $\boldsymbol{x}_{e}$ includes sector, $\mathrm{BRD}$, the interaction between sector and BRD, lunar phase, and lunar phase advanced 7 days, and $z_{e}$ the interaction between sector and sampling trip. For the stout whiting fishery, $\boldsymbol{x}_{e}$ includes gear type (i.e. fish trawl net or Danish seine), lunar phase, and lunar phase advanced 7 days and $z_{e}$ the interaction between gear type and sampling trip.

\section{Swept area method}

Discard weights were obtained from 4012 trawls from individual nets. These are the same data as those used for the retained catch method, except the data frame was restructured to include information on individual net deployments, specifically net head rope length, bottom trawl duration, and discard weight. As the swept area method does not require retained catch, some additional observations that were not included in the retained catch method data were added. The research charter data were also included in this model because the charters used commercial fishing nets and undertook all sampling on commercial fishing grounds. Hence, there was no reason to assume any difference between the catch rate of discards $\left(\mathrm{kg} \mathrm{ha}^{-1}\right)$ from commercial vessels undertaking normal fishing activities and the research charters. For net $n$ from trawl $i$, the swept area $S A_{i, n}$ in hectares was defined as:

$$
S A_{i, n}=L_{i, n} S_{i, n} h_{i, n} f_{i, n} / 10000
$$

where $L_{i, n}$ is the net head rope length in metres; $S_{i, n}$ is the speed of the trawl in metres per hour; $h_{i, n}$ is the bottom trawl duration in hours; $f_{i, n}$ is a trawl net spread factor from Sterling (2000) of $0.650,0.704,0.794,0.764,0.704$ for single, twin, triple, quad, and five gear, respectively. Division by 10000 converts square metres to hectares.

In the 1990s, the stout whiting license holders harvested whiting using single fish trawl nets with extended sweeps of $128 \mathrm{~m}$. The swept area for the fish trawl was estimated to be the sum of the combined sweeps and net head rope lengths multiplied by a spread factor of 0.289 . The Danish seine uses two sweeps each with a maximum regulated length of $2500 \mathrm{~m}$ which was estimated to sweep 110.5 ha per deployment.

The discard rate $D_{i, n}\left(\mathrm{~kg} \mathrm{ha}{ }^{-1}\right)$, was calculated as: $D_{i, n}=d_{i, n} / S A_{i, n}$, where $d_{i, n}$ is the discard weight for net $n$ from each trawl or seine deployment $i$. Similar to the effort method, the discard rate was modelled using the gamma regression model of GLMMs with the log link function. The relationship between the mean rate $\mu_{s}$ and covariates was described as follows,

$$
\ln \left(\mu_{s}\right)=\alpha_{s}+\boldsymbol{x}_{s}^{t} \boldsymbol{\beta}_{\mathrm{s}}+\boldsymbol{z}_{s}^{t} \boldsymbol{b}_{s}
$$

where $\alpha_{s}$ is the intercept, $\boldsymbol{x}_{s}$ and $\boldsymbol{z}_{s}$ are the column vectors of covariates for fixed and random effects, respectively and $\boldsymbol{\beta}_{\mathrm{s}}$ and $\boldsymbol{b}_{\boldsymbol{s}}$ are their respective coefficients. For all sectors other than stout whiting, $\boldsymbol{x}_{s}$ includes sector, BRD, the interaction between sector and BRD, sampling programme, lunar phase, and lunar phase advanced 7 days; $z_{s}$ the interaction between sector and trawl shot number. For the stout whiting fishery, $\boldsymbol{x}_{\boldsymbol{s}}$ includes gear type (i.e. trawl net or Danish seine), lunar phase, and lunar phase advanced 7 days; $z_{s}$ the interaction between gear type and sampling trip.

\section{Bayesian inference}

Model fitting and prediction for the three methods were conducted within the Bayesian framework. Bayesian analysis is a likelihood-based approach with sensible uncertainty setting in probability (i.e. priors) for model parameters. Bayes' theorem is utilized to derive the posterior distributions of the parameters (i.e. the probability distribution of parameter conditioned on the data) accordingly. Bayesian inference for the parameters and model prediction is then carried out through the derived posterior distributions (Robert, 2007; Gelman et al., 2013).

Markov chain Monte Carlo (MCMC) techniques have been widely used in Bayesian analysis for acquiring the posterior distributions of the model parameters (Robert, 2007; Gelman et al., 2013). The obtained MCMC samples for the parameters are then used to calculate posterior means, standard errors, and quantiles for constructing credible intervals for parameter inference and model prediction.

Model fitting and prediction for GLMMs were performed using R package "rstanarm" version 2.17.4 (Goodrich et al., 2018) in the environment of $\mathrm{R}$ version 3.5.1 ( $\mathrm{R}$ Core Team 2018). Package rstanarm is a module of Stan (Carpenter et al., 2017) which is a probabilistic programming language supporting various, efficient MCMC algorithms to undertake Bayesian analysis. Specifically, the command stan_glmer of rstanarm was utilized for GLMM fitting. The priors specified for parameters were weakly informative priors (Gelman et al., 2008) which are also the default priors in rstanarm. A total of 30000 MCMC samples for each parameter were acquired from three MCMC iteration chains, each of which ran 20000 iterations with the last $50 \%$ of MCMC samples retained. MCMC convergence was examined by using Rhat statistics with a value less than 1.1 (Gelman et al., 2013) and visual evaluation of trace plots.

\section{Predicting annual discards}

The annual weight of discards for the whole QECOTF from 1988 to 2014 was defined as the mean of the three methods (i.e. retained catch, effort and swept area). For each method, the discard weight for a given sector and year was denoted as the product of the sector's adjusted discard rate and the relevant fixed scale factor for the sector and year. For the retained catch method, the scale factor was the reported retained catch $(\mathrm{kg})$ from the logbook data for the sector in the year. For the effort method, the scale factor was fishing effort (boat days) from the logbook data for the sector in the year. For the swept area method, the scale factor was the product of mean daily swept area 
(ha boat day ${ }^{-1}$ ) and total effort (boat days) for the sector in the year. Mean daily swept area was calculated using data on the number and size of nets towed by fishers and their trawl speeds (see O'Neill et al. 2003 and O'Neill and Leigh 2007 for details) from 1988 to 2014, as well as mean daily trawl duration and net spread factors. The mean daily trawl duration (i.e. length of time that nets were towed along the bottom, hour) was based on onboard observations of commercial vessels and the number of hours fishers reported trawling each day in their logbook.

The adjusted discard rates for the sectors were acquired as the means of the GLMMs' predictions based on the model fitting data for the sectors. By implementing the MCMC samples of the model parameters, the GLMMs then produced the MCMC samples of the adjusted discard rates for the sectors. The MCMC samples of the adjusted discard rates and the scale factors were then used to produce the MCMC samples of the annual weight of discards for the whole QECOTF from 1988 to 2014. The posterior means and 95\% credible intervals of the discard rates for the sectors and annual discards were derived from their MCMC samples accordingly.

\section{Results \\ Modelling discard rates}

For all the three methods, the shallow water eastern king prawn fishery was used as the reference level that sectors were compared against because it often had the highest discard rates. Testing for BRD effects was undertaken for five of the eight sectors, but was not possible for the red spot king prawn, Moreton Bay and stout whiting sectors due to a lack of observations from vessels without the devices. Note that as the stout whiting fishery targets a species of finfish, it is not required to use BRDs, other than TEDs.

For the retained catch method, discard rates $\left(\mathrm{kg} \mathrm{kg}^{-1}\right)$ in the deep water eastern king prawn and scallop sectors were significantly lower than the shallow water eastern king prawn reference sector (Table 2a). BRDs significantly reduced discard rates, although their effect was inconsistent and associated with significant increases in some sectors. The scallop fishery had the largest reduction attributed to BRDs. Results for the sampling programme type indicated that the discard rate from research charters was significantly higher than that of commercial fishing. The advanced lunar phase effect was significant indicating that discard rates varied significantly between waxing and waning lunar phases.

For the effort method, discard rates $\left(\mathrm{kg}_{\mathrm{boat}} \mathrm{day}^{-1}\right)$ were significantly higher in the red spot king prawn and tiger and endeavour sectors, compared to the shallow water eastern king prawn fishery (Table 2b). BRDs had no significant effect. As this dataset used only commercial vessel fishing observations, sampling programme type and shot number were not included in this analysis.

For the swept area method, most sectors had significantly lower discard rates $\left(\mathrm{kg} \mathrm{ha}^{-1}\right)$ compared to the shallow water eastern king prawn sector (Table 2c). The deep water eastern king prawn fishery had the lowest discard rate. Overall, BRDs significantly reduced discard rates, but their effect was inconsistent across sectors. The largest reduction due to BRDs occurred in the scallop fishery. Sampling programme type indicated that the discard rate was significantly higher during research charters compared to commercial fishing. Lunar phase and advanced lunar phase both had significant effects, indicating that discard rates vary with absolute lunar luminance and between the wanning and waxing phases.
Table 2. Posterior mean, $2.5 \%$ and $97.5 \%$ quantiles of coefficients $\boldsymbol{\beta}$ of the three models for retained catch, fishing effort and swept area.

\begin{tabular}{lrrr}
\hline & Mean & \multicolumn{1}{c}{ LB } & \multicolumn{1}{c}{ UB } \\
\hline (a) Retained catch method & & & \\
Banana prawn & -0.061 & -0.295 & 0.176 \\
Eastern king prawn (deep) & $-\mathbf{1 . 1 4 8}$ & $-\mathbf{1 . 3 9 3}$ & $-\mathbf{0 . 9 0 1}$ \\
Moreton Bay & -0.306 & -0.719 & 0.105 \\
Red spot king prawn & -0.006 & -0.216 & 0.207 \\
Scallop & $-\mathbf{0 . 9 8 9}$ & $-\mathbf{1 . 2 0 3}$ & $-\mathbf{0 . 7 5 2}$ \\
Tiger and endeavour prawn & -0.128 & -0.340 & 0.084 \\
BRDs & $-\mathbf{0 . 2 6 9}$ & $-\mathbf{0 . 4 0 0}$ & $-\mathbf{0 . 1 4 0}$ \\
Sampling programme (charter) & $\mathbf{0 . 5 6 6}$ & $\mathbf{0 . 4 3 7}$ & $\mathbf{0 . 6 9 6}$ \\
Lunar phase & 0.063 & -0.102 & 0.231 \\
Lunar phase advanced & $\mathbf{0 . 2 2 7}$ & $\mathbf{0 . 0 8 7}$ & $\mathbf{0 . 3 7 0}$ \\
Banana prawn with BRDs & $-\mathbf{0 . 1 8 6}$ & $-\mathbf{0 . 3 5 6}$ & $-\mathbf{0 . 0 1 4}$ \\
Eastern king prawn (deep) with BRDs & $\mathbf{0 . 2 9 6}$ & $\mathbf{0 . 1 2 9}$ & $\mathbf{0 . 4 6 5}$ \\
Scallop with BRDs & $-\mathbf{0 . 5 2 2}$ & $-\mathbf{0 . 6 7 3}$ & $-\mathbf{0 . 3 7 1}$ \\
Tiger and endeavour prawn with BRDs & $\mathbf{0 . 1 8 9}$ & $\mathbf{0 . 0 4 6}$ & $\mathbf{0 . 3 3 2}$ \\
(b) Effort method & & & \\
Banana prawn & -0.508 & -1.690 & 0.640 \\
Eastern king prawn (deep) & -0.803 & -2.004 & 0.380 \\
Red spot king prawn & $\mathbf{0 . 6 4 8}$ & $\mathbf{0 . 0 8 8}$ & $\mathbf{1 . 2 1 3}$ \\
Scallop & 0.232 & -0.310 & 0.769 \\
Tiger and endeavour prawn & $\mathbf{0 . 5 8 3}$ & $\mathbf{0 . 0 1 9}$ & $\mathbf{1 . 1 4 7}$ \\
BRDs & -0.462 & -1.483 & 0.545 \\
Lunar phase & -0.174 & -0.383 & 0.038 \\
Lunar phase advanced & -0.135 & -0.329 & 0.057 \\
Banana prawn with BRDs & 0.750 & -0.397 & 1.919 \\
Eastern king prawn (deep) with BRDs & 0.836 & -0.278 & 1.959 \\
(c) Swept area method & & & \\
Banana prawn & $-\mathbf{0 . 2 4 0}$ & $-\mathbf{0 . 4 2 9}$ & $-\mathbf{0 . 0 5 5}$ \\
Eastern king prawn (deep) & $-\mathbf{1 . 8 5 2}$ & $-\mathbf{2 . 0 5 0}$ & $-\mathbf{1 . 6 5 3}$ \\
Moreton Bay & -0.165 & -0.488 & 0.165 \\
Red spot king prawn & $-\mathbf{0 . 3 3 3}$ & $-\mathbf{0 . 5 0 1}$ & $-\mathbf{0 . 1 6 4}$ \\
Scallop & -0.188 & -0.382 & 0.002 \\
Tiger and endeavour prawn & $-\mathbf{0 . 4 0 6}$ & $-\mathbf{0 . 5 7 1}$ & $-\mathbf{0 . 2 4 6}$ \\
BRDs & $-\mathbf{0 . 2 9 9}$ & $-\mathbf{0 . 3 9 7}$ & $-\mathbf{0 . 2 0 1}$ \\
Sampling programme (charter) & $\mathbf{0 . 3 5 0}$ & $\mathbf{0 . 2 5 7}$ & $\mathbf{0 . 4 4 3}$ \\
Lunar phase & $-\mathbf{0 . 1 5 5}$ & $-\mathbf{0 . 2 7 9}$ & $-\mathbf{0 . 0 3 1}$ \\
Lunar phase advanced & $-\mathbf{0 . 1 5 0}$ & $-\mathbf{0 . 2 5 7}$ & $-\mathbf{0 . 0 4 2}$ \\
Banana prawn with BRDs & $\mathbf{0 . 3 4 3}$ & $\mathbf{0 . 2 0 4}$ & $\mathbf{0 . 4 8 3}$ \\
Eastern king prawn (deep) with BRDs & $\mathbf{0 . 4 3 4}$ & $\mathbf{0 . 2 9 5}$ & $\mathbf{0 . 5 7 2}$ \\
Scallop with BRDs & $-\mathbf{0 . 5 6 2}$ & $-\mathbf{0 . 6 9 5}$ & $-\mathbf{0 . 4 2 7}$ \\
Tiger and endeavour prawn with BRDs & $\mathbf{0 . 1 3 7}$ & $\mathbf{0 . 0 3 2}$ & $\mathbf{0 . 2 4 2}$ \\
\hline Trefereng & & & \\
\hline
\end{tabular}

The reference level for fishing sector was the shallow ( $<50$ fathoms) water eastern king prawn fishery. The $2.5 \%$ and $97.5 \%$ quantiles represent the lower bound (LB) and upper bound (UB) for $95 \%$ credible intervals. Coefficients are significant (bold) if zero falls outside of the associated $95 \%$ credible intervals; otherwise, they are not statistically significant.

For the stout whiting sector, there were no significant differences in discard rates between trawl fishing and the Danish seine, for all three methods (Table 3). Both lunar phase effects were significant for the retained catch method (Table 3a).

Adjusted discard rates for the retained catch method ranged between 5.71 (5.44; 5.99, 0.025 and 0.0975 quantiles, respectively) $\mathrm{kg} \mathrm{kg}^{-1}$ in the shallow water eastern king prawn sector and 0.52 $(0.51 ; 0.53) \mathrm{kg} \mathrm{kg}^{-1}$ in the Danish seine stout whiting fishery, respectively (Figure 2).

In contrast, the stout whiting fishery had the highest adjusted discard rates based on the effort method (Figure 2) ranging between $2362.29(1941.19 ; 2877.17) \mathrm{kg}$ boat $\mathrm{day}^{-1}$ and 3005.62 (2207.87; 4096.63) $\mathrm{kg}$ boat day $^{-1}$ for otter trawl and Danish seine 
Table 3. Posterior mean, $2.5 \%$ and $97.5 \%$ quantiles of coefficients $\boldsymbol{\beta}$ of the three models for retained catch, fishing effort and swept area methods for the stout whiting sector.

\begin{tabular}{lrlr}
\hline & Mean & LB & \multicolumn{1}{c}{ UB } \\
\hline (a) Retained catch method & & & \\
$\quad$ Danish seine & -0.082 & -1.205 & 1.064 \\
$\quad$ Lunar & $-\mathbf{0 . 1 4 8}$ & $-\mathbf{0 . 2 1 7}$ & $-\mathbf{0 . 0 7 8}$ \\
$\quad$ Lunar advanced & $-\mathbf{1 . 0 4 7}$ & $-\mathbf{1 . 1 0 5}$ & $-\mathbf{0 . 9 8 9}$ \\
(b) Effort method & & & \\
$\quad$ Danish seine & 0.473 & -0.111 & 1.106 \\
$\quad$ Lunar & -0.184 & -0.982 & 0.598 \\
$\quad$ Lunar advanced & 0.325 & -0.429 & 1.023 \\
(c) Swept area method & & & \\
$\quad$ Danish seine & -0.158 & -0.679 & 0.377 \\
$\quad$ Lunar & -0.237 & -0.814 & 0.323 \\
$\quad$ Lunar advanced & -0.028 & -0.572 & 0.482 \\
\hline
\end{tabular}

The reference level was the stout whiting trawl fishery. The $2.5 \%$ and $97.5 \%$ quantiles represent the lower bound (LB) and upper bound (UB) for the $95 \%$ credible intervals. Coefficients are significant (bold) if zero falls outside of the associated $95 \%$ credible intervals; otherwise, they are not statistically significant.

gear, respectively. Adjusted discard rates for the remaining sectors were comparatively low and ranged between a maximum of $782.87(708.57 ; 864.96) \mathrm{kg}$ boat day $^{-1}$ and a minimum of 170.87 $(128.20 ; 228.00) \mathrm{kg}$ boat day ${ }^{-1}$ for the red spot king prawn and Moreton Bay sectors, respectively.

Adjusted discard rates for the swept area method ranged between a maximum of $9.19(8.81: 9.59) \mathrm{kg} \mathrm{ha}^{-1}$ in the shallow water eastern king prawn fishery and a minimum of 1.45 (1.39:1.51) $\mathrm{kg} \mathrm{ha}^{-1}$ in the deep water eastern king prawn fishery (Figure 2).

\section{Total discards}

Annual discard estimates and their 95\% credible intervals for each sector and method are provided in Figure 3. In general, there were significant differences in discard estimates between methods for most sectors, particularly prior to 2000 , and no single method produced consistently larger or smaller estimates. From 1988 to 2000, the tiger and endeavour prawn fishery (Figure $3 \mathrm{e}$ ) produced between approximately 15000 and $30000 \mathrm{t}$ of discards annuallysignificantly more than any other sector. After 2000, following the introduction of major management changes, there was a marked decline in several sectors, including the tiger and endeavour prawn fishery, red spot king prawn fishery (Figure 3c), Moreton Bay (Figure 3g), and particularly the scallop fishery (Figure 3f). Annual discards for the banana prawn fishery (Figure 3d) were highly variable, possibly because catch and effort in this sector are strongly influenced by regional rainfall and river flows. For all sectors except the deep water eastern king prawn fishery (Figure 3b), discards declined or remained relatively stable from 1988 to 2014.

Mean annual discards for the whole QECOTF peaked at 67053 t (64 053; 71 164) in 1997 and declined markedly over the following decade, particularly from 2000 to 2001 (Figure 4). Prior to 2000, the fishery generated over $46000 \mathrm{t}$ of discards annually. Annual discards from 2011 to 2014 remained relatively stable at approximately $21000 \mathrm{t}$. Narrowing of the lower and upper bounds after 2000 is attributed to including BRD effects in the adjusted discard rates at this time. Annual fishing effort (Figure 4) also peaked in 1997 at 114267 boat days and was strongly correlated with annual discards. The retained catch peaked at $20013 \mathrm{t}$ in 1993 (Figure 4) and declined thereafter to a mean of approximately $9400 \mathrm{t}$ from 2011 to 2014. The ratio of discards to retained catch declined from about 3.5:1 in the late 1990s to about 2.3:1 from 2011 to 2014 .

\section{Discussion}

Partitioning the fishery into sectors increased the amount of variation in discard rates that could be explained, as all three models indicated significant differences between sectors (Table 2). It is noteworthy that the sector rank changed with the method used, e.g. the shallow water eastern king prawn fishery had among the highest discard rates for the retained catch and swept area methods, but the stout whiting fishery produced the highest discard rates for the effort method (Figure 2). This is because the fish trawl nets and the Danish seines are much more efficient at herding and catching finfish compared to the prawn and scallop nets used, and therefore the amount of discards generated per day in the stout whiting fishery was $4-6$ times that of the other sectors.

Differences between the shallow (i.e. $<50 \mathrm{fm}$ ) and deep water $(>50 \mathrm{fm}$ ) eastern king prawn sectors reflect the effect of depth on discard rates. Discard rates were 3-6 times higher in the shallow water compared to the deep water fishery, based on the retained catch and swept area methods (Figure 2), even though both sectors target the same species at similar latitudes. The reason these two sectors had similar discard rates for the effort method is because the deep water vessels are permitted to use much larger nets than their shallow water counterparts (detailed in Table 1). Adjusted discard rates for the effort method were 462.7 (347.1; $617.4) \mathrm{kg}_{\text {boat day }}{ }^{-1}$ and $392.8(341.7 ; 451.4) \mathrm{kg}_{\text {boat }} \mathrm{day}^{-1}$, for the shallow and deep water sectors, respectively.

The study used discard measures from two sampling programme types (commercial fishing and research charters) and found that discard rates were significantly higher in research charters (Table 2a and c). Parameter estimates from research charters were about $75 \%$ higher for the retained catch method and $42 \%$ higher for the swept area method. The relatively large effect for the retained catch method should be interpreted with caution as it may simply indicate that researchers are not as skilled as commercial fishers at catching the target species, thus resulting in the research charter data producing higher discard weights per $\mathrm{kg}$ of retained catch. Nevertheless, the findings suggest that using discard rates based on research charter data may overestimate discards. It is important to note therefore that the annual discard estimates in Figures 3 and 4 were derived using adjusted discard rates based solely on commercial fishing data.

The trend in total annual discards was characterized by a general increase from 1988 to a peak of $67053 \mathrm{t}$ in 1997, followed by a marked decline over the next decade to a plateau of about $21000 \mathrm{t}$ from 2011 to 2014 (Figure 4). Based on Kelleher's (2005) estimate that Australia produced $120981 \mathrm{t}$ of discards annually from 1992 to 2001, the study suggests that the QECOTF accounted for approximately $50 \%$ of the nation's discards. The high correlation between discards and fishing effort (Figure 4) is not surprising given that the estimates were largely a function of effort in two of the three methods (i.e. effort method and the swept area method).

Results for the deep water eastern king prawn fishery indicate that discards approximately doubled from 1988 to 2014 (Figure $3 \mathrm{~b}$ ), which contrasts markedly with the other sectors and the overall QECOTF trend (Figure 4). This is largely due to an increase in fishing effort in this sector over the period, which is partly due to displaced fishing effort out of the Great Barrier Reef Marine Park, following a substantial increase in fishing closures 
Retained catch method

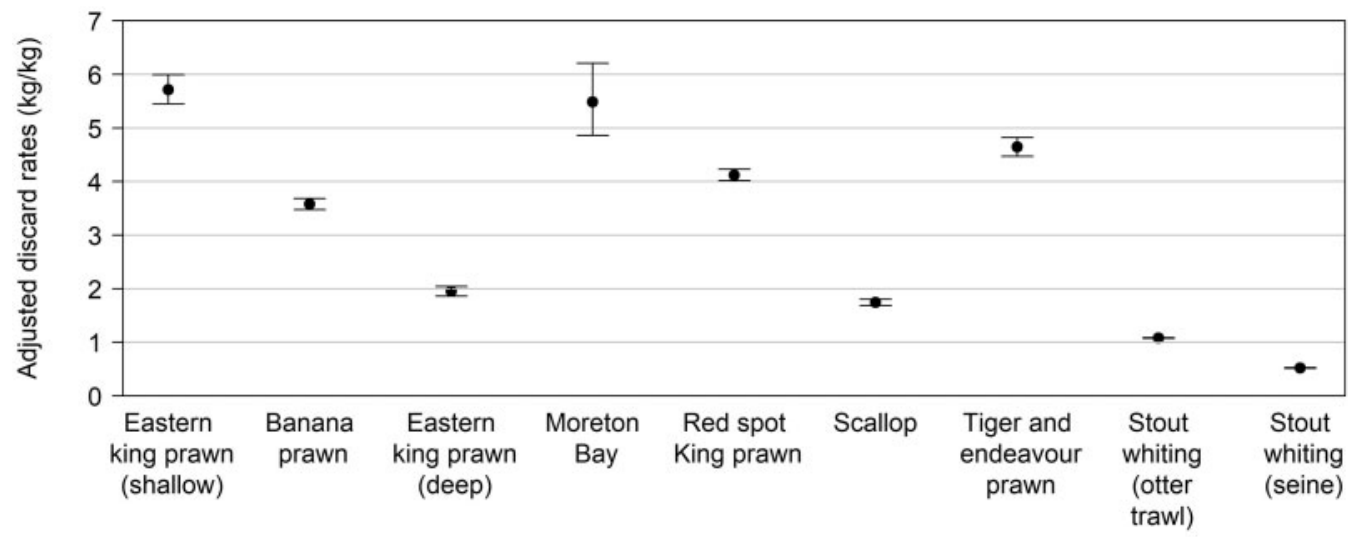

Effort method

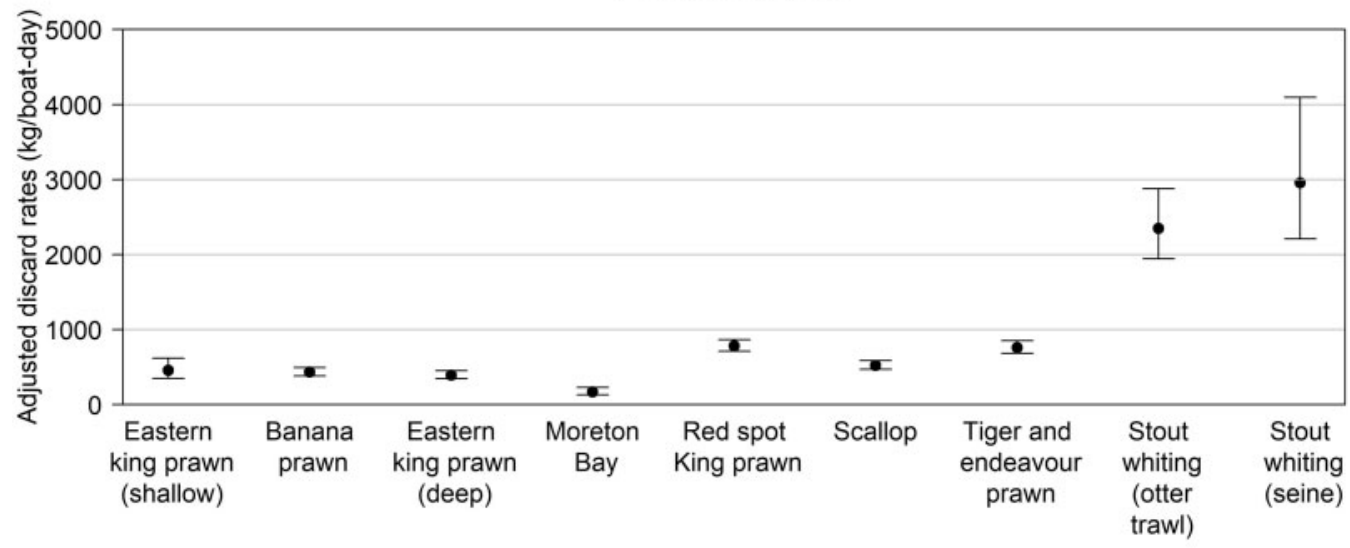

Swept area method

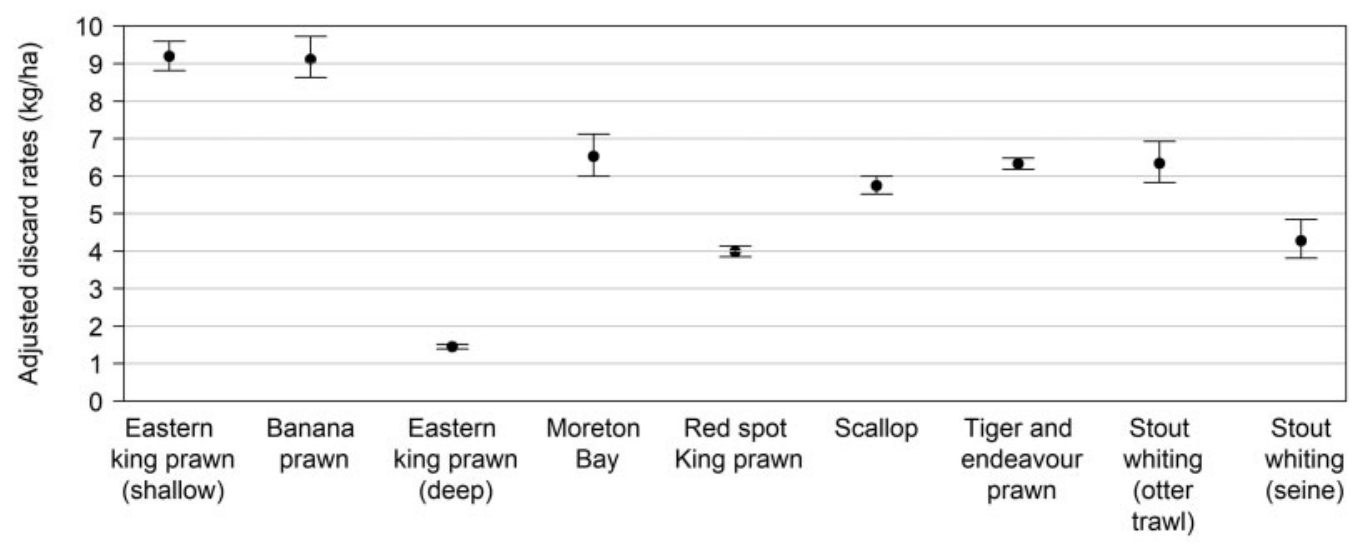

Figure 2. Posterior means, $2.5 \%$ and $97.5 \%$ quantiles of adjusted discard rates for each sector of the QECOTF, including the stout whiting trawl and Danish seine fishery. The predictions are based on pooled BRD and sampling programme effects. Vertical bars are $95 \%$ credible intervals composed of $2.5 \%$ and $97.5 \%$ quantiles as lower and upper bounds.

in the Park in 2004 (Fernandes et al., 2005; Macintosh et al., 2010).

\section{Influence of BRDs}

BRDs generally resulted in significant reductions in discard rates, however, their effects varied across sectors and methods
(Table 2). Significant reductions in discard rates have been demonstrated in QECOTF by undertaking research charters to evaluate TEDs and other BRDs (Courtney et al., 2006, 2008, 2014). It is more difficult to quantify BRD effects while sampling on-board commercial vessels during their normal fishing activities, due to a lack of experimental control needed to obtain repeated measures from nets with and without BRDs. 
(a)

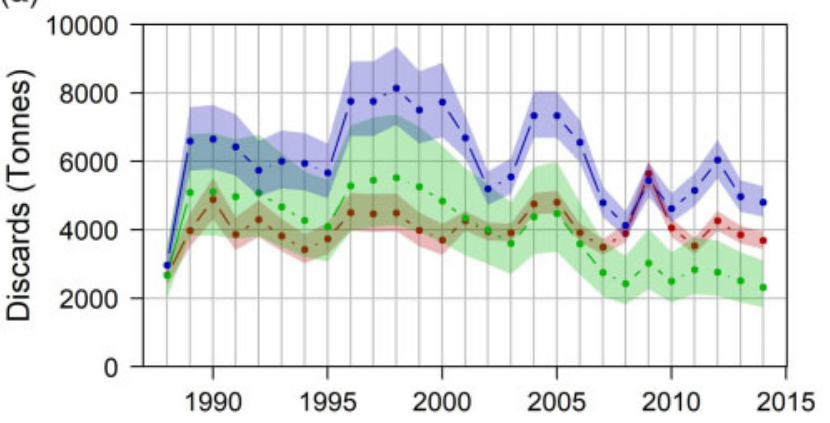

(c)

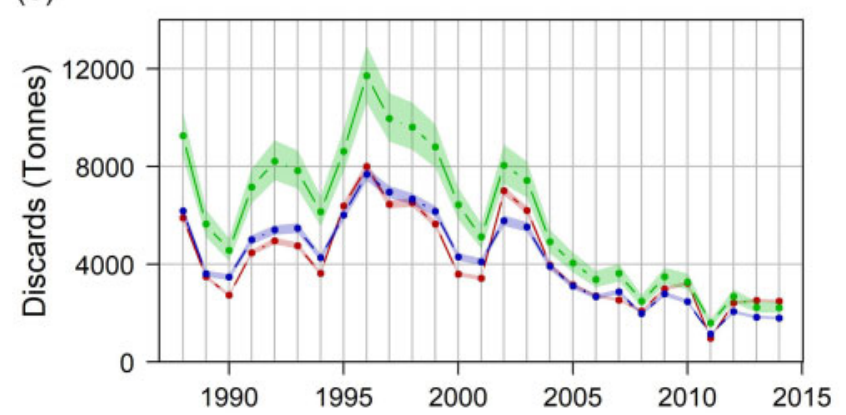

(e)

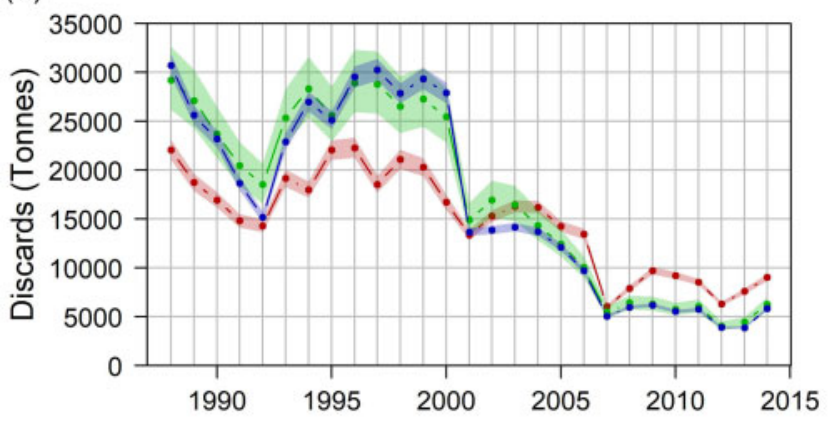

(g)

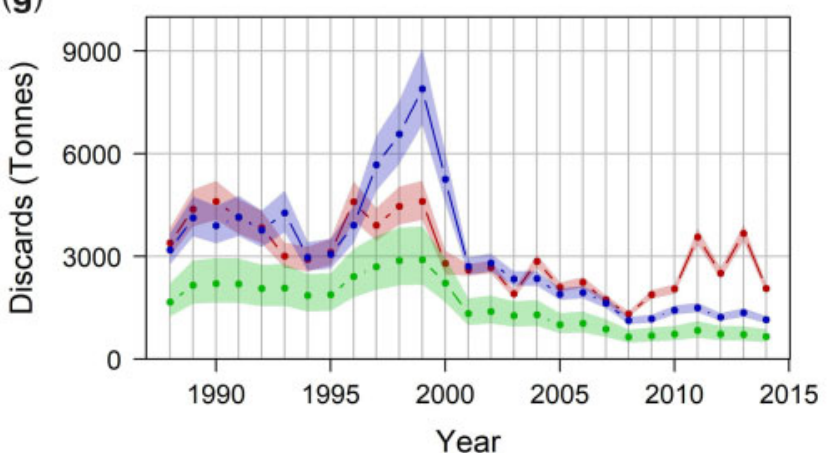

(b)

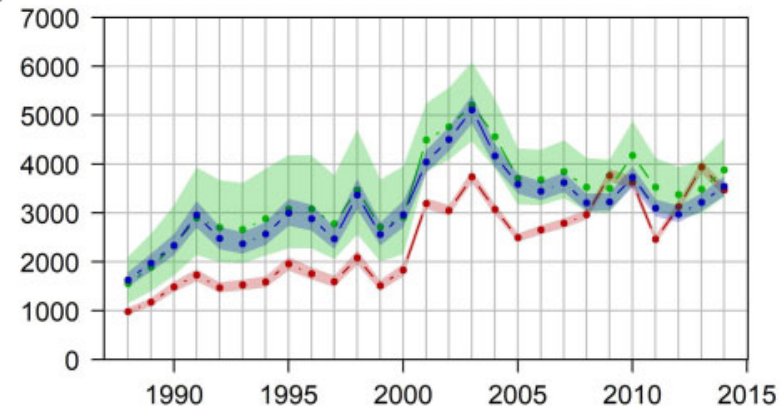

(d)

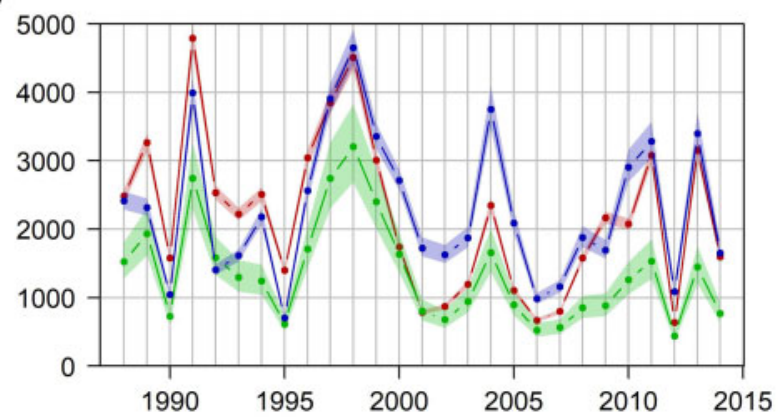

(f)

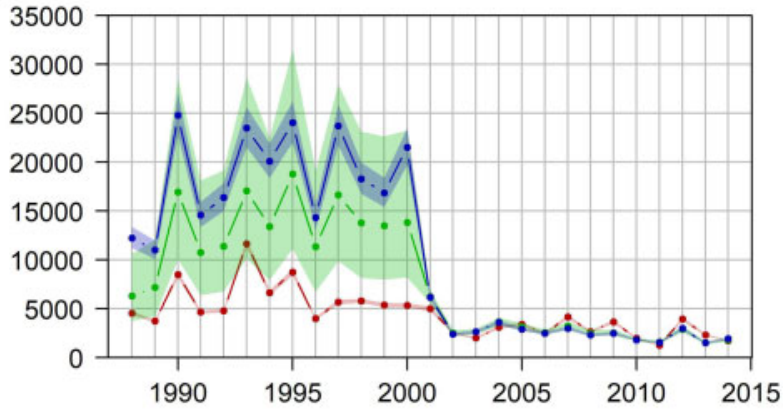

(h)

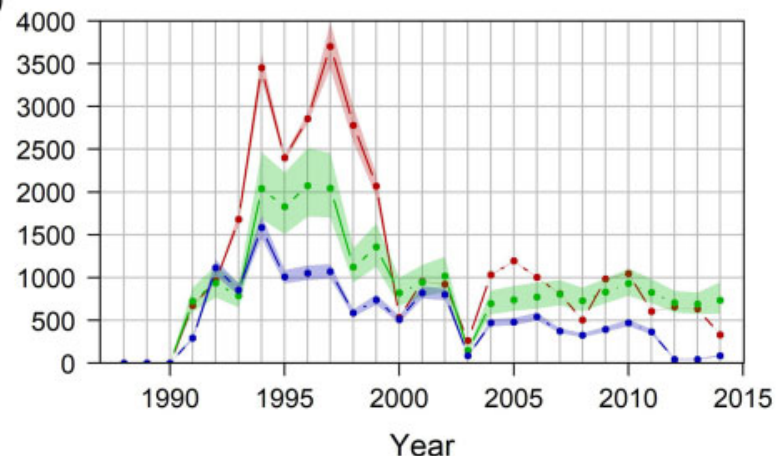

Figure 3. Posterior means and $95 \%$ credible intervals of annual discards from each of the three methods and fishing sector comprising the QECOTF, from January 1988 to December 2014. Means for the retained catch, effort, and swept area methods are red, green, and blue lines, respectively. (a) Shallow water eastern king prawn; (b) deep water eastern king prawn; (c) red spot king prawn; (d) banana prawn; (e) tiger and endeavour prawn; ( $f$ ) scallop; (g) Moreton Bay; and (h) stout whiting.

The significant positive BRD parameter values in Table 2a and c, which indicate an increase in discard rate, appear counter intuitive and difficult to explain, however, all such positive effects were obtained from sampling on-board commercial vessels during their normal fishing activities, and were therefore subject to limited experimental control.

In summary, research charters allow for greater experimental control needed to evaluate BRDs, but the results indicate that discard 


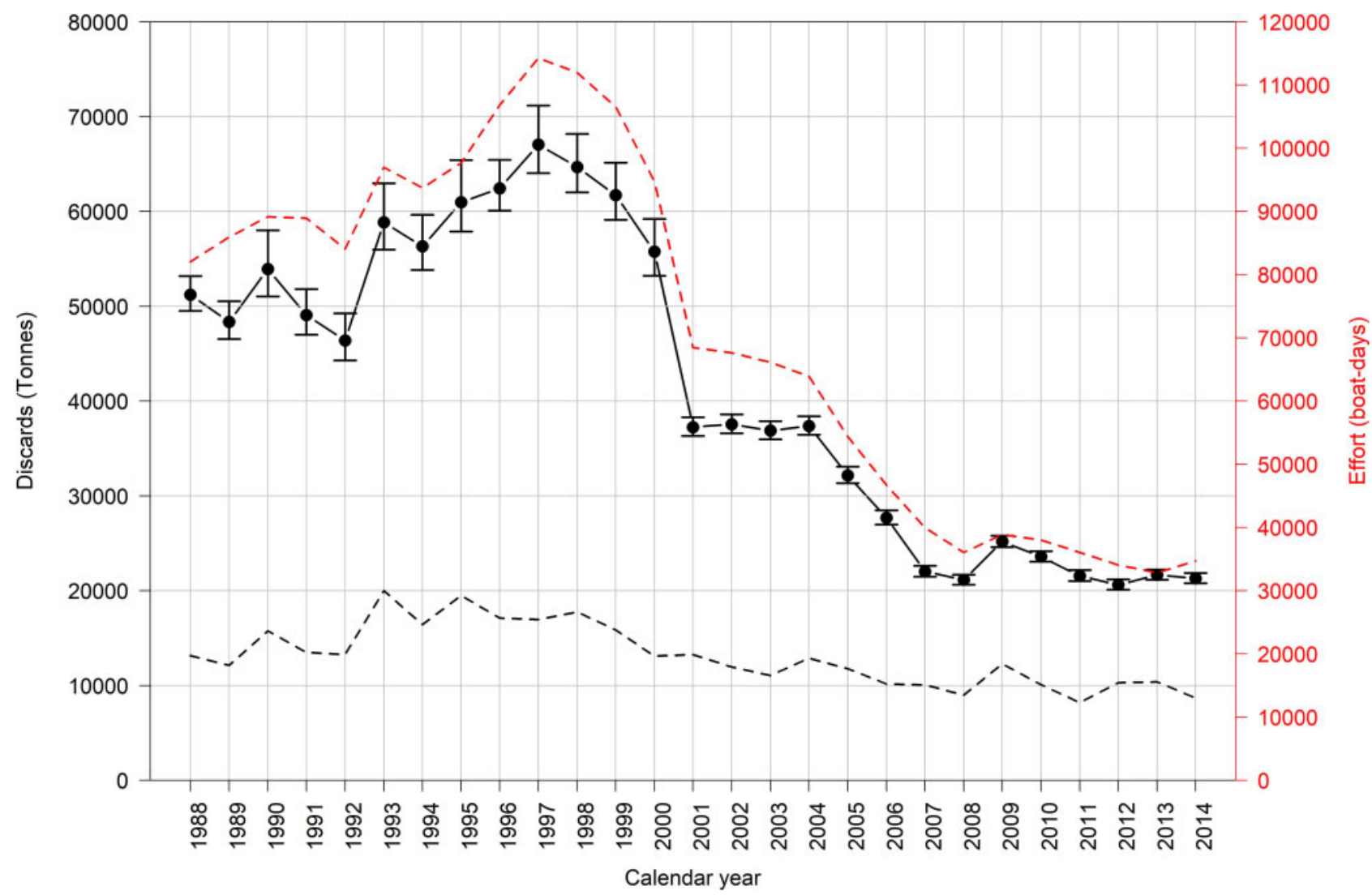

Figure 4. Posterior prediction of mean annual discards in tonnes (black dotted line) from the QECOTF from 1988 to 2014 , inclusive. Also provided are logbook data showing total annual fishing effort in boat days (red dashed line) and total annual retained catch in tonnes (black dashed line) and from all sectors. The lower and upper bounds of the bars are posterior $2.5 \%$ and $97.5 \%$ quantiles.

rates from such charters tend to be higher than those obtained during normal commercial fishing activities and therefore should be omitted when estimating the amount of discards produced by a fishery. The lack of significant BRD reductions on commercial vessels in some sectors as presented here should be interpreted with caution. The lack of a significant BRD effect for the effort model (Table 2b) was also likely influenced by the need to sum discard weights to whole boat days, which prevented the model from explaining variation between trawls.

The retained catch and swept area models (Table 2a and c) both indicated significant discard rate reductions in the scallop fishery due to BRDs. In the period 2000-2002, mandatory management measures implemented in the QECOTF required all trawl nets to have both a TED and a second BRD installed. The marked decline in discards in the scallop fishery after 2000 (Figure 3f) is largely attributed to TEDs, which have been shown to significantly reduce the catch rate of sponges (Porifera spp.) which comprised over 60\% of the discards weight (Courtney et al., 2008) in this sector. The implementation of TEDs and other BRDs contributed to a reduction in discards in the other sectors, particularly the tiger and endeavour prawn sector (Figure 3e). However, as sponges are not a major component of the discard assemblages for these sectors, the decline was not as marked.

\section{Comparison of methods}

For most sectors, the three methods produced considerably different annual discard estimates (Figure 3), with the largest differences in the order of 2-3-fold in some years, particularly prior to
2001. After 2001, differences between the estimates reduced and the discard trajectories merged. The effort method had the largest 95\% credible intervals (Figure 3), possibly because the discard rate model had the fewest explanatory terms, due to the need to sum discard weights to whole boat days. The swept area method probably produced the most reliable discard estimates, because the adjusted discard rate (i.e. $\mathrm{kg} \mathrm{ha}^{-1}$ ) took into account more factors, including net size and trawl duration. However, we acknowledge that many fisheries may not have access to such detailed information required to quantify swept area.

The retained catch method is relatively simple, with few data requirements, but it often produced the lowest discard estimates (Figure 3). As fishers adopt more effective BRDs over time, the relationship between retained catch and discards will change. This appears to be the case for the QECOTF where the discardsretained catch weight ratio declined from 3.5:1 to 2.3:1 over the period considered (Figure 4). Thus, if discard estimates are to be based on the retained catch, then it is important to be aware of factors, such as the adoption of effective BRDs and other technological fishing improvements, which affect the discards-retained catch weight relationship.

Several studies have shown that fishing power in the QECOTF sectors has increased by $0.4-3.6 \%$ annually (O'Neill et al., 2003; O'Neill and Leigh, 2007; Braccini et al., 2012; Kienzle et al., 2014). All of these studies modelled logbook daily target species catch as a function of vessel characteristics, including vessel length, engine horse power, trawl speed, propeller size, global 
positioning system, net head rope length, BRDs, and other gears. The increased power of an average boat day over the study period (1988-2014) was not considered in the effort model discard estimates. However, the swept-area method did incorporate change in trawl speed, net size, and hours trawled per day, when deriving swept area.

The overall effect of increasing fishing power is likely to increase discards as a function of fishing effort. However, caution is needed when extrapolating fishing power effects on discards because the fishing power estimates are the result of modelling target species catch-not discards. Furthermore, while the adoption of some technologies, such as larger net head rope size, is likely to increase discards, the effect of other technologies, such as global positioning systems, is unclear. Importantly, fishing power-related increases in discards in the QECOTF are likely to have been at least partly offset by the mandatory adoption of BRDs in the early 2000s.

In conclusion, there remains a strong need to manage the amount of discards that are produced by commercial fishing on local, national, and international scales (Zeller et al., 2018; Pérez Roda et al., 2019). The methods and results presented here provide a quantitative long-term trend in discards produced by the QECOTF, which is one of the largest commercial fisheries in Australia. The total annual discard estimates are relatively robust because they were based on the mean of three methods and utilized adjusted discard rates that took account of several influential factors. It is anticipated that the fishery managers will incorporate the findings into their discards assessment and monitoring management plans.

\section{Acknowledgements}

Funding for this analysis was provided by the Department of Agriculture and Fisheries Queensland and the Australian Fisheries Research and Development Corporation (FRDC Project 2015/14). The following assisted with the measurement of the catch and discard data from the QECOTF: K. Chilcott, S. Gaddes, C. Van Der Geest, C. Rose, S. McCulloch, G. Leese, B. Watson, P. Kyne, M. Tonks, D. Roy, R. Wallace, B. Schemel, M. McLennan, J. Robins, and J. McGilvray. We thank the following crew members for their support and seamanship during the research charters: C. Flaherty, W. Flaherty, D. Flaherty, P. Gaddes, P. Pearson, B. Ehrke, and R. Hansen. Brian Paterson provided helpful comments on a previous draft of this article. Data on discards were obtained under the following permits: (i) Great Barrier Reef Marine Park permit approval numbers G01/437 and G05/14443, (ii) Queensland Primary Industries Animal Ethics Approval Reference Number Bribie 58/05/05, (iii) Queensland Parks and Wildlife Environmental Protection Agency Permit Number WISP03205105, and (iv) the Commonwealth DEWHA Permit E2005-60221.

\section{References}

Alverson, D. L., Freeberg, M. H., Pope, J. G., and Murawski, S. A. 1994. A global assessment of fisheries bycatch and discards. FAO Fisheries Technical Paper, 330. 233 pp.

Braccini, J. M., O’Neill, M. F., Campbell, A. B., Leigh, G. M., and Courtney, A. J. 2012. Fishing power and standardized catch rates: implications of missing vessel-characteristic data from the Australian eastern king prawn (Melicertus plebejus) fishery. Canadian Journal of Fisheries and Aquatic Sciences, 69: 797-809.
Brewer, D., Heales, D., Milton, D., Dell, Q., Fry, G., Venables, B., and Jones, P. 2006. The impact of turtle excluder devices and bycatch reduction devices on diverse tropical marine communities in Australia's northern prawn trawl fishery. Fisheries Research, 81: 176-188.

Broadhurst, M. K., Millar, R. B., Kennelly, S. J., Macbeth, W. G., Young, D. J., and Gray, C. A. 2004. Selectivity of conventional diamond- and novel square-mesh codends in an Australian estuarine penaeid-trawl fishery. Fisheries Research, 67: 183-194.

Carpenter, B., Gelman, A., Hoffman, M. D., Lee, D., Goodrich, B., Betancourt, M., and Brubaker, M. 2017. Stan: a probabilistic programming language. Journal of Statistical Software, 76: 1-32.

Condie, H. M., Catchpole, T. L., and Grant, A. 2014. The short-term impacts of implementing catch quotas and a discard ban on English North Sea otter trawlers. ICES Journal of Marine Science, 71: 1266-1276.

Courtney, A. J., Campbell, M. J., and Ballam, D. E. 2007a. A collaborative extension programme by the Queensland Department of Primary Industries and Fisheries, SeaNET and Ecofish for the development and adoption of square mesh codends in select prawn and scallop trawl fisheries in Queensland. Fisheries Research and Development Corporation (FRDC) Final Report number 2005/054. 64 pp.

Courtney, A. J., Campbell, M. J., Roy, D. P., Tonks, M. L., Chilcott, K. E., and Kyne, P. M. 2008. Round scallops and square meshes: a comparison of four codend types on the catch rates of target species and by-catch in the Queensland (Australia) saucer scallop (Amusium balloti) trawl fishery. Marine and Freshwater Research, 59: 849-864.

Courtney, A. J., Campbell, M. J., Tonks, M. L., Roy, D. P., Gaddes, S. W., Haddy, J. A., and Kyne, P. M. 2014. Effects of bycatch reduction devices in Queensland's (Australia) deepwater eastern king prawn (Melicertus plebejus) trawl fishery. Fisheries Research, 157: $113-123$.

Courtney, A. J., Haddy, J. A., Campbell, M. J., Roy, D. P., Tonks, M. L., Gaddes, S. W., Chilcott, K. E. et al. 2007b. Bycatch weight, composition and preliminary estimates of the impact of bycatch reduction devices in Queensland's trawl fishery. Fisheries Research and Development Corporation (FRDC) Final Report No. 2000/170. 307 pp.

Courtney, A. J., Schemel, B. L., Wallace, R., Campbell, M. J., Mayer, D. G., and Young, B. 2010. Reducing the impact of Queensland's trawl fisheries on protected sea snakes. Fisheries Research and Development Corporation (FRDC) Final Report Number 2005/053. 121 pp.

Courtney, A. J., Tonks, M. L., Campbell, M. J., Roy, D. P., Gaddes, S. W., Kyne, P. M., and O’Neill, M. F. 2006. Quantifying the effects of bycatch reduction devices in Queensland's (Australia) shallow water eastern king prawn (Penaeus plebejus) trawl fishery. Fisheries Research, 80: 136-147.

Davies, R. W. D., Cripps, S. J., Nickson, A., and Porter, G. 2009. Defining and estimating global marine fisheries bycatch. Marine Policy, 33: 661-672.

Elfes, C. T., Livingstone, S. R., Lane, A. L. V., Sanders, K. L., Courtney, A. J., Gatus, J. L., and Guinea, M. 2013. Fascinating and forgotten, the conservation status of marine elapid snakes. Herpetological Conservation and Biology, 8: 37-52.

FAO. 1997. Report of the Technical Consultation on Reduction of Wastage in Fisheries. Tokyo, Japan, 28 October-1 November 1996.

Fernandes, L., Day, J., Lewis, A., Slegers, S., Kerrigan, B., Breen, D., Cameron, D. et al. 2005. Establishing representative no-take areas in the Great Barrier Reef: large-scale implementation of theory on marine protected areas. Conservation Biology, 19: 1733-1744.

Gelman, A., Carlin, J. B., Stern, H. S., Dunson, D. B., Vehtari, A., and Rubin, D. B. 2013. Bayesian Data Analysis, 3rd edn (Chapman \& Hall/CRC Texts in Statistical Science). Chapman \& Hall/CRC, New York, USA. 
Gelman, A., Jakulin, A., Pittau, M. G., and Su, Y.-S. 2008. A weakly informative default prior distribution for logistic and other regression models. The Annals of Applied Statistics, 2: 1360-1383.

Goodrich, B., Gabry, J., Ali, I., and Brilleman, S. 2018. rstanarm: Bayesian applied regression modeling via Stan. R package version 2.17.4. http://mc-stan.org/.

Gullet, W. 2003. Enforcing bycatch reduction in trawl fisheries: legislating for the use of turtle exclusion devices. Environmental and Planning Law Journal, 20: 195-210.

Hill, B. J., and Pashen, A. J. 1986. Management of the Queensland east coast otter trawl fishery: An historical review and future options. In Fisheries Management: Theory and Practice in Queensland, pp. 146-166. Ed. by T. J. A. Hundloe. Griffith University, Brisbane, Australia.

Kelleher, K. 2005. Discards in the world's marine fisheries. An update. FAO Fisheries Technical Paper, 470. 131 pp.

Kennelly, S. J., and Broadhurst, M. K. 2014. Mitigating the bycatch of giant cuttlefish Sepia apama and blue swimmer crabs Portunus armatus in an Australian penaeid-trawl fishery. Endangered Species Research, 26: 161-166.

Kennelly, S. J., Liggins, G. W., and Broadhurst, M. K. 1998. Retained and discarded by-catch from oceanic prawn trawling in New South Wales, Australia. Fisheries Research, 36: 217-236.

Kienzle, M., Courtney, A. J., and O'Neill, M. F. 2014. Environmental and fishing effects on the dynamics of brown tiger prawn (Penaeus esculentus) in Moreton Bay (Australia). Fisheries Research, 155: 138-148.

Macintosh, A., Bonyhady, T., and Wilkinson, D. 2010. Dealing with interests displaced by marine protected areas: a case study on the Great Barrier Reef Marine Park Structural Adjustment Package. Ocean and Coastal Management, 53: 581-588.

O'Neill, M. F., Courtney, A. J., Turnbull, C. T., Good, N. M., Yeomans, K. M., Staunton Smith, J., and Shootingstar, C. 2003. Comparison of relative fishing power between different sectors of the Queensland trawl fishery, Australia. Fisheries Research, 65: 309-321.

O'Neill, M. F., and Leigh, G. M. 2007. Fishing power increases continue in Queensland's east coast trawl fishery, Australia. Fisheries Research, 85: 84-92.

Pérez Roda, M. A., Gilman, E., Huntington, T., Kennelly, S. J., Suuronen, P., Chaloupka, M., and Medley, P. 2019. A Third Assessment of Global Marine Fisheries Discards. FAO Fisheries and Aquaculture Technical Paper No. 633. FAO, Rome. 78 pp.

Pitcher, C. R., Ellis, N., Venables, W. N., Wassenberg, T. J., Burridge, C. Y., Smith, G. P., and Browne, M. 2016. Effects of trawling on sessile megabenthos in the Great Barrier Reef and evaluation of the efficacy of management strategies. ICES Journal of Marine Science, 73: i115-i126.

R Core Team. 2018. R: a language and environment for statistical computing. R Foundation for Statistical Computing, Vienna, Austria. https://www.R-project.org/.
Robert, C. P. 2007. The Bayesian Choice: From Decision-Theoretic Foundations to Computational Implementation, 2nd edn. Springer, New York, USA.

Robins, J. B. 1995. Estimated catch and mortality of sea turtles from the East Coast Otter Trawl Fishery of Queensland, Australia. Biological Conservation, 74: 157-167.

Robins, J. B., and Courtney, A. J. 1998. Status report on bycatch within the Queensland trawl fishery. In Establishing Meaningful Targets for Bycatch Reduction in Australian Fisheries, pp. 24-45. Ed. by C. Buxton, and S. Eayrs. Australian Society for Fish Biology, Hobart.

Robins, J., Eayrs, S., Campbell, M., Day, G., and McGilvray, J. 2000. Commercialisation of bycatch reduction strategies and devices within northern Australian prawn trawl fisheries. Fisheries Research and Development Corporation (FRDC) Final Report Number 1996/254. 40 pp.

Robins-Troeger, J. B. 1994. Evaluation of the Morrison soft TED: prawn and bycatch variation in Moreton Bay, Queensland. Fisheries Research, 19: 205-217.

Robins-Troeger, J. B., Buckworth, R. C., and Dredge, M. C. L. 1995. Development of a trawl efficiency device (TED) for Australian prawn fisheries. II. Field evaluations of the AusTED. Fisheries Research, 22: 107-117.

Rochet, M. J., Catchpole, T., and Cadrin, S. 2014. Bycatch and discards: from improved knowledge to mitigation programmes. ICES Journal of Marine Science, 71: 1216-1218.

State of Queensland. 1999. Fisheries (East Coast Trawl) Management Plan 1999. Subordinate legislation of the Fisheries Act 1994, Office of the Queensland Parliamentary Council. State of Queensland. 296 pp. https://www.legislation.qld.gov.au/ LEGISLTN/REPEALED/F/FisherECTMP99_02K_031219.pdf (last accessed 22 October 2019).

Sterling, D. 2000. The Physical Performance of Prawn Trawling Otter Boards and Low Opening Systems. Sterling Trawl Gear Services, Brisbane.

Stobutzki, I., Blaber, S., Brewer, D., Fry, G., Heales, D., Miller, M., Milton, D. et al. 2000. Ecological sustainability of bycatch and biodiversity in prawn trawl fisheries. Fisheries Research and Development Corporation (FRDC) Final Report No. 96/257. 512 pp.

Watson, R. A., Dredge, M. L. C., and Mayer, D. G. 1990. Spatial and seasonal variation in demersal trawl fauna associated with a prawn fishery on the central Great Barrier Reef, Australia. Australian Journal of Marine and Freshwater Research, 41: 65-77.

Watson, R. A., and Goeden, G. 1989. Temporal and spatial zonation of the demersal trawl fauna of the central Great Barrier Reef. Memoirs of the Queensland Museum, 27: 611-620.

Zeller, D., Cashion, T., Palomares, M., and Pauly, D. 2018. Global marine fisheries discards: a synthesis of reconstructed data. Fish and Fisheries, 19: 30-39. 